\title{
The Problem of the Inefficacy of Knowledge in Early Buddhist Soteriology
}

Ryan Showler

$\mathrm{E}$ arly Buddhism has been described as a "gnostic soteriology"1 in that it sees the chief cause of life's unsatisfactoriness to be ignorance of certain metaphysical truths, and that once this ignorance is eliminated through awareness of the true nature of reality, the suffering that is rooted in ignorance goes away with it. In what follows, I will describe a significant problem that early Buddhism faces, as does any gnostic soteriology, and propose a solution to the problem. This is a quasi-analytic study of early Buddhist epistemology in that it applies some of the standard ideas about knowledge that have guided analytic epistemology for some time to a specific problem that confronts the early Buddhist attempt to claim that knowing some truths about reality will transform us in some significant way. When speaking of "early Buddhism" in what follows, I intend those teachings contained in the Pali canon, which the Theravada tradition has sought to preserve. Historically Buddhism quickly moves away from the Theravada focus on nirvana and into the various schools of the "Great Vehicle" of the Mahayana Tradition. My characterization of Buddhism as a gnostic soteriology refers only to a form of Buddhism that may be limited to the earliest part of the movement and the conservative wing (Theravada) that has sought to preserve its earliest form ever since.

I begin with a fuller explanation of what Buddhism as a gnostic soteriology implies, and the rather large problem that such a system faces. By definition, a soteriology is a system of thought that has as its goal the salvation or deliverance of its adherents. A soteriology is gnostic when it claims that the primary vehicle through which this salvation is accomplished is knowledge of some truth or set of truths. Thus in soteriological systems of the gnostic variety knowledge of some truth or truths is purported to have transforming power of some kind. The "truths" these systems enjoin their followers to know are diverse, but they often revolve around some metaphysical claims that run contrary to our commonsense views about reality.

1 David Burton, Buddhism, Knowledge and Liberation (Burlington, Vermont: Ashgate Publishing, 2004), 1-2. 
Early Buddhism fits this description of gnostic soteriology "in so far as it identifies knowledge, or gnosis, as a necessary condition for liberation." 2 To be specific, early Buddhism identifies knowledge of the Four Noble Truths and the Three Characteristics of Existence as essentially leading to the detachment that brings about liberation, or nirvana. The first of the Four Noble Truths has been traditionally interpreted in the West as claiming that life is filled with suffering. The Pali term translated suffering (dukkha) is probably better rendered otherwise. One of the more effective translations is that given by Mark Epstein. Epstein defines dukkha as "pervasive unsatisfactoriness."3 It is not that life contains only suffering. Buddhism is well aware of the many joys and pleasures found in the human experience. This first truth is designed to point out that the impermanence of all things results in a condition that will disappoint those who expect permanence. ${ }^{4}$ As human beings, we have a tendency to expect the permanence of many different things in many different ways. The result of these expectations is a pervasively unsatisfactory condition.

The second of the Four Noble Truths claims that this pervasively unsatisfactory condition arises because of our craving and attachment to self and the world. Here is where the metaphysical claims of early Buddhism especially come into play. The Three Characteristics of Existence tell us that (1) all things are impermanent, (2) all things produce suffering, and (3) all things are without self. ${ }^{5}$ The third characteristic has been the topic of much debate over the years, but early Buddhism seems committed to the thesis that, contrary to our commonsense views, there is no self in any permanent, stable sense. The "aggregates" that we typically think of as composing our selves are as much a part of the flux that characterizes reality as anything else. The pervasive unsatisfactoriness of the human condition is produced by our thinking otherwise and clinging to notions of the permanence of self and others.

The third of the Four Noble Truths simply infers that if the pervasive unsatisfactoriness of the human condition is the result of our craving and attachment, then this unsatisfactoriness can be eliminated by doing away with the craving and attachment. And the fourth truth tells us how to do away with this craving and attachment: through the Noble Eightfold Path, a set of exercises that revolve around thought and action appropriate to the metaphysical claims contained in the Three Characteristics of Existence.

Early Buddhism appears to alternately claim that (1) knowledge of the above truths and (2) active engagement in the Noble Eightfold Path produce release from the pervasively unsatisfactory condition in which all humans find themselves. One way of interpreting these alternate claims is to say that it is active engagement in the Noble Eightfold Path itself that produces the genuine knowledge that liberates, that this knowledge requires more than mere assent. In what follows, I will offer an argument for this interpretation. The most

\footnotetext{
${ }^{2}$ Ibid., 2.

${ }^{3}$ Mark Epstein, Thoughts Without a Thinker (New York: Basic Books, 1995), 46.

${ }^{4}$ Walpola Rahula, What the Buddha Taught (New York: Grove Press, 1974), 17-18.

${ }^{5}$ Burton, op cit., 2.
} 


\section{EARLY BUDDHIST SOTERIOLOGY}

important part of early Buddhism's soteriological claims appears to be the notion that the self does not exist. Early Buddhism appears to claim that much of what goes into making possible the pervasively unsatisfactory nature of human life is found in our clinging to the notion of self. Thus, Steven Collins refers to "the Buddhist doctrine of not-self as a soteriological strategy." 6 Eliminating our clinging to the notion of self will eliminate the unsatisfactoriness of life. Our clinging to the notion of self will be automatically eliminated when we have genuine knowledge that self does not exist.

I will mention here two other systems of thought that present a similar relationship between knowledge and some sort of salvific transformation. Hinduism in its earlier forms appears to claim that knowledge of "the unity of all things" produces the liberation that is the ultimate goal of Hindus (moksha). Collins writes that "in Brahmanical thought the final truth and goal of the religious thought was that self (ätman) and universe (brahman) were essentially the same." Knowledge of this truth is claimed to produce liberation from the cycle of rebirth (samsära). And Ancient Stoicism appears to claim that knowledge of the radical determination of the universe will produce the tranquility we all seek in the face of a world that often seems to work against us. Pierre Hadot writes, "The Stoic experience consists in becoming sharply aware of the tragic situation of human beings, who are conditioned by fate. It would seem that we are not free at all, for it is not up to us to be beautiful, strong, healthy, or rich, to feel pleasure, or to escape suffering. All these things depend on causes which are external to us." 8 Knowing this supposed metaphysical truth about the universe allows us to begin "focusing on reality as it is, without adding to it value judgments inspired by conventions, prejudices, or the passions . . .." 9 These value judgments are what produce the suffering from which we seek deliverance.

The problem which these systems of thought face is that it appears possible to know these metaphysical "truths" and still not be transformed in the ways that the systems have promised. Since my primary concern here is early Buddhism, let us look closer at this problem in the context of the claims early Buddhism seems to be making. David Burton does a wonderful job of laying out the problem:

I do not seem to be ignorant about the impermanence of entities. I appear to understand that entities have no fixed essence and that they often change in disagreeable ways. I seem to understand that what I possess will fall out of my possession. I apparently accept that all entities must pass away. And I seem to acknowledge that my

\footnotetext{
${ }^{6}$ Steven Collins, Selfless Persons (Cambridge: Cambridge University Press, 1982), 12.

${ }^{7}$ Ibid., 76.

8 Pierre Hadot, What is Ancient Philosophy?, trans. by Michael Chase (Cambridge, Massachusetts: Belknap Press, 2002), 127.

${ }^{9}$ Ibid., 136.
} 
craving causes suffering. Yet I am certainly not free from craving and attachment. Buddhism....appears to say that my understanding of the three characteristics should liberate me. But the reality is that I continue to crave and suffer. How, then, might one preserve the common Buddhist claim that knowledge of the three characteristics of existence results in liberation in the face of this objection?10

Thus we are left with the question of why knowledge of Buddhism's basic metaphysical claims fails to have the transforming power Buddhism claims it has.

Burton proposes two possible ways Buddhism might respond to the above problem: (1) using the distinction between knowledge by description and knowledge by acquaintance, and (2) using the distinction between conscious and unconscious beliefs. In (1) the argument is made that in those cases where it appears that knowledge of Buddhism's metaphysical claims fails to transform us, it is likely that we only possess knowledge by description, a weaker form of knowledge. It is knowledge by acquaintance, the stronger form, which triggers transformation. Burton dismisses this argument as untenable on the basis that

the impermanence of entities is normally accessible to people's perceptions. One perceives all sorts of changes, and numerous instances of entities coming into existence and passing away. And in the course of one's life, one often perceives the impermanence and lack of fixed nature of entities that are extremely dear to oneself. This often produces a direct experience of suffering. This is not merely knowledge by description. It is knowledge one has from direct perception. And yet one still craves and gets attached to these impermanent entities. ${ }^{11}$

Notice here that Burton neglects to argue that the notion that self does not exist is readily accessible to the senses. This will become an issue in what follows.

The argument that uses the distinction between conscious and unconscious beliefs in order to understand the inefficacy of knowledge in early Buddhism is closer to what I would like to propose. In this argument it is claimed, according to Burton, "Perhaps Unawakened people continue to crave despite apparently understanding the three characteristics because they have an unconscious and false belief that things are permanent, have an abiding essence, and will not cause suffering if coveted."12 Perhaps this unconscious

\footnotetext{
${ }^{10}$ Burton, op cit., 31.

11 Ibid., 36.

12 Ibid., 40.
} 


\section{EARLY BUDDHIST SOTERIOLOGY}

false belief nullifies or, at the very least, interrupts the conscious true belief in the metaphysical claims Buddhism makes. As a result, the knowledge one possesses on the conscious level is prevented from performing its transforming work by these unconscious beliefs. My discomfort with this proposal is due to the difficulty of substantiating claims about unconscious thoughts. Burton expresses a similar wariness. ${ }^{13}$ But I do think this proposal identifies an important component of the nature of belief that will allow us to think about the problem of the inefficacy of knowledge in Buddhism in a different but related way. In order to present my proposal, I first need to say some things about the standard way analytic philosophers have talked about knowledge.

Analytic philosophers have typically talked about knowledge under the following definition: knowledge is true justified belief. This definition presents knowledge in terms of three conditions that must be met in order for genuine knowledge to exist. Edmund Gettier shook the world of analytic epistemology in 1963 when he published a short paper containing examples of these three conditions being met in ways that seem to preclude our calling them instances of knowledge. ${ }^{14}$ While Gettier's article sparked a lively debate (primarily about when the justification condition of the standard account of knowledge is met and when it is not), analytic philosophers have continued to think about knowledge in terms of these three conditions.

The analytic discussion of knowledge is concerned primarily with propositional knowledge, or the knowledge that a particular proposition is the case. It appears that a person has knowledge of a proposition when (1) the person believes the proposition, (2) the person is appropriately justified in believing the proposition, and (3) the proposition is in fact true. In cases where it appears that knowledge of early Buddhist metaphysics fails to have the promised power to transform, we take for granted that we are, in fact, dealing with genuine knowledge. In other words, we take for granted that the three conditions of the standard account of knowledge are met. I would like to suggest that a more fruitful way of interpreting what is happening is that what has been characterized here as knowledge actually fails to meet the standard criteria for genuine knowledge; namely, it fails to meet the belief condition.

Let us take a closer look now at the belief condition of the standard account of knowledge. D. W. Hamlyn calls belief "that state of mind that is appropriate to truth." 15 What state of mind is appropriate to truth? Assent. Affirmation. I believe a proposition when I enter a mental position of assent and affirmation where that proposition is concerned. In my mind I say, "Yes, that proposition is the case." I would like to argue that in some cases it is much more difficult to meet the belief condition than we might think, especially when we are dealing with counterintuitive propositions (as we are in early Buddhism).

\footnotetext{
13 Ibid., 44-46.

${ }^{14}$ Edmund Gettier, "Is Justified True Belief Knowledge?," in Analysis 23 (1963), 121 -

123.

${ }^{15}$ D. W. Hamlyn, The Theory of Knowledge (Garden City, New York: Anchor Books, 1970), 87.
} 
Let me offer a more precise definition of what I intend by the phrase "counterintuitive proposition." A counterintuitive proposition is one that is met with persistent recalcitrant evidence. Much of the time we are dealing with beliefs that our experience of the world only confirms. In these cases, belief may be a matter of simple assent. But if it is the case that some true propositions run contrary to our experience of the world, it is likely that meeting the belief condition and maintaining it where these propositions are concerned will require considerable effort. My main claim here is that believing counterintuitive propositions requires more than simple assent. It requires something that can stave off the persistent illusion.

It is useful here to consider a relatively simple example of a counterintuitive proposition and the difficulty one faces when attempting to believe it. Take the following proposition: "The sun does not rise and set." This proposition is true. In spite of the fact that our conventional speech concerning the motion of the sun and earth pretends that the sun is in constant motion around the earth, we have good reasons to believe that the motion of the earth around the sun produces an illusion that is difficult to shake. This illusion has led past cultures to hatch a variety of wild speculations concerning the nature of the sun. For example, Collins speaks of the Vedic interpretation of the sun's rising and setting as "the perpetual death and rebirth of the sun; each night it dies over the horizon, and enters the waters underground, where it becomes an embryo, before being reborn with the dawn."16 But even though we are acquainted with the kind of reasoning that justifies our belief in the above proposition ("The sun does not rise and set."), we are confronted by continual evidence to the contrary. And meeting the belief condition becomes a challenge in the face of this evidence. I can remind myself that the sun is not in motion and instead the earth's motion is producing an illusion, but it will not be long before I watch the sun appear or disappear over the horizon and find myself thinking of it as an object in motion. ${ }^{17}$

Because counterintuitive propositions are met with a constant barrage of contrary evidence, the only way to believe them is to return that barrage with a set of exercises specifically designed to stave off particular kinds of recalcitrant evidence. In the case of the sun's apparent motion around the earth, these exercises might involve a few key points from astronomy that remind us of the way our solar system works, or a mental image of a picture of the earth taken from space. It is likely in this case that it will not take much to push us back into proper thinking. But if we neglect these exercises, it is almost certain that we will find ourselves slipping back into thinking in line with the persistent illusion.

The metaphysical propositions early Buddhism enjoins us to believe, especially the notion that there is no self, are counterintuitive in the sense described above. Thus, believing them will require much more than simply

${ }^{16}$ Collins, op cit., 42.

17 Of course, we know that the sun is actually in slight motion around the center of our solar system, but this is not the kind of motion that would produce its "rising" and "setting." 


\section{EARLY BUDDHIST SOTERIOLOGY}

affirming their truth. It will require a set of exercises specifically designed to stave off the particular recalcitrant evidence with which they are met. My claim is that the Noble Eightfold Path contains this set of exercises, and thus that genuine belief in the metaphysical propositions Buddhism enjoins us to believe is to be found in active engagement in this set of exercises.

Collins agrees of early Buddhism that "many of the central ideas of its ideal, normative system are counter-intuitive, and seem prima facie unlikely vehicles for the religious aspirations of the ordinary man in society." 18 The Buddha himself spoke of the truths through which he was enlightened as counterintuitive in nature. For example, in the Samyutta Nikayya he says,

Enough now with trying to teach

What I have found with so much hardship;

This Dhamma is not easily understood by those

oppressed by lust and hate.

Those fired by lust, obscured by darkness,

Will never see this abstruse Dhamma,

Deep, hard to see, subtle,

Going against the stream. ${ }^{19}$

Collins also writes, "It is thus, according to Buddhism itself, only a first step cognitively to pay allegiance to the denial of self. To "realize" the truth of it personally - both to understand it and to make it real - involves an affective change in personality and psychology only brought about by long and arduous practice." 20

It appears that the same move is made in other gnostic soteriologies. In some sense Hindu yogas are designed to bring a person to genuine belief in the unity of all things. Ancient Stoicism also enjoins us to perform specific exercises when we are met with evidence contrary to the metaphysical claims of the Stoic system. Pierre Hadot speaks of the metaphysical claims of the Stoics as "a complete reversal of the usual way of looking at things." 21

There are both sensory and non-sensory forms of recalcitrant evidence where counterintuitive propositions are concerned. When dealing with the notion of no-self, we are confronted with several different kinds of contrary evidence. For example, we are continually faced with the kinds of internal recalcitrant evidence discussed by both Hume and Kant in their critical examinations of the notion of self. They suggest that even if the self does not exist, an illusion that it does is produced (Hume) or reason finds the idea of a self necessary to make sense of the constant stream of experience (Kant). If this is the case, then even in the absence of a self the fiction or idea that there is a self exerts continual pressure. We might call this "psychological evidence."

\footnotetext{
${ }^{18}$ Collins, op cit., 18

19 The Connected Discourses of the Buddha: A Translation of the Samyutta Nikayya, trans. by Bikkhu Bodhi (Boston: Wisdom Publications, 2000), 231-232.

${ }^{20}$ Collins, op cit., 19.

${ }^{21}$ Hadot, op cit., 133.
} 
We are also confronted with evidence involving the conventions of language. The Noble Eightfold Path is designed to mount a counterattack against this evidence by enjoining us to continually remind ourselves of the reasoning that led us to the counterintuitive metaphysical claims (Right Understanding), by enjoining us to modify various areas of our lives in order to act as if the counterintuitive claims are true (Right Thought, Right Speech, Right Action, Right Livelihood), and by enjoining us to regularly practice a set of meditative exercises designed to turn our gaze away from the illusion of self (Right Mindfulness, Right Concentration). All of this is to be undergirded by a deep commitment to the process itself (Right Effort).

I do not wish to ignore the fact that Burton himself suggests that Buddhism is prepared to meet the challenge of what I have called the problem of the inefficacy of knowledge in Buddhism through its prescription of a path. He writes,

... the Buddhists can claim that their notion of liberating knowledge needs to be understood in the context of Buddhist spiritual life as a whole. The objection stems from examining Buddhist knowledge-claims in isolation from the other aspects of Buddhist practice...Liberating knowledge needs to be viewed as the outcome of a process of training and the thorough knowledge which finally ends craving is simply the last step of a path of discipline and reflection...The Buddhist spiritual discipline, as expressed in formulae such as the Eightfold Path, includes cognitive and non-cognitive dimensions. And the non-cognitive dimensions might be further divided into affective, volitional and behavioural subcategories. Buddhism generally advocates a systematic training which is meant to transform the practitioner's intellect, emotions and will, as well as verbal and bodily actions. ${ }^{22}$

What I am doing here is suggesting that these various elements of transformation are all tied to one's believing the basic metaphysical claims of early Buddhism, and that reaching the state where one believes them is especially difficult because of their counterintuitive nature.

What I have argued above appears to suggest that we can pass in and out of assent where counterintuitive propositions are concerned. When I neglect the exercises that stave off the persistent illusion, I pass out of assent and back into belief in the illusion. When I renew my commitment to those exercises, I find myself passing back into assent. Am I claiming that we do not really believe that the sun does not rise and set? If belief simply means that we will answer in line with the proposition when we are questioned about it, then

22 Burton, op cit., 65. 


\section{EARLY BUDDHIST SOTERIOLOGY}

those of us who understand the motion of the earth around the sun clearly believe the proposition continuously regardless of our participation in any set of exercises. But if belief has both a cognitive and an affective or behavioral component, then it appears that we do pass in and out of assent where this proposition is concerned depending on what we have or have not done recently to remind ourselves of its truth. ${ }^{23}$

Belief almost certainly means not only that we will answer in line with a proposition when questioned (cognitive assent), but also that we will act in line with it when opportunity arises (non-cognitive assent). ${ }^{24}$ Much of the difficulty we have with believing counterintuitive propositions appears to involve our non-cognitive assent. While Buddhism's Noble Eightfold Path is designed to meet the cognitive difficulties we face where belief in certain metaphysical claims is concerned, its prescriptions are geared primarily toward the deeper problems related to our non-cognitive transformation. And while the possibility of passing in and out of assent will continue to exist while one is on the path, the ultimate goal of this soteriological system is to bring a person to the place where the belief condition is met once and for all. Whether or not such a state is actually realizable is open to debate.

Liberal Arts Division, Yavapai College, United States

\section{References}

Bodhi, Bikkhu, ed., The Connected Discourses of the Buddha: A Translation of the Samyutta Nikeaya, trans. by Bikkhu Bodhi (Boston: Wisdom Publications, 2000).

Burton, David, Buddhism, Knowledge and Liberation (Burlington, Vermont: Ashgate Publishing, 2004).

Collins, Steven, Selfless Persons (Cambridge: Cambridge University Press, 1982). Epstein, Mark, Thoughts Without a Thinker (New York: Basic Books, 1995).

Gettier, Edmund, "Is Justified True Belief Knowledge?," in Analysis 23 (1963).

Hadot, Pierre, What is Ancient Philosophy?, trans. by Michael Chase (Cambridge, Massachusetts: Belknap Press, 2002).

Hamlyn, D. W., The Theory of Knowledge (Garden City, New York: Anchor Books, 1970).

Rahula, Walpola, What the Buddha Taught (New York: Grove Press, 1974).

${ }^{23}$ Collins discusses at length R. F. Gombrich's appeal to this distinction between the cognitive and affective components of belief in his discussion of the difficulty of believing Buddhism's metaphysical claims. See Collins, op cit., 18.

${ }^{24}$ I include here all three of Burton's subcategories of the non-cognitive dimensions of the Noble Eightfold Path (affective, volitional, and behavioral) in the phrase "non-cognitive assent." While it may seem strange to speak of assent that is not cognitive, when I genuinely believe a proposition it almost certainly implies that I act as if that proposition were true. 